\title{
Association of coffee and caffeine intake with irritable bowel syndrome in adults
}

\author{
Glareh Koochakpoor \\ Maragheh University of Medical Sciences https://orcid.org/0000-0003-2937-7445 \\ Asma Salari-Moghaddam \\ Tehran University of Medical Sciences \\ Ammar Hassanzadeh Keshteli \\ Alberta Health \\ Ahmad Esmaillzadeh ( $\nabla$ a-esmaillzadeh@tums.ac.ir ) \\ Peyman Adibi \\ Isfahan University of Medical Sciences
}

\section{Research}

Keywords: Coffee, caffeine, irritable bowel syndrome, IBS

Posted Date: June 18th, 2020

DOl: https://doi.org/10.21203/rs.3.rs-35477/v1

License: () (i) This work is licensed under a Creative Commons Attribution 4.0 International License. Read Full License 


\section{Abstract}

Background: The aim of this study was to investigate the association between coffee and caffeine intake and odds of IBS and its severity in adult population.

Methods: In this cross-sectional study, dietary intakes of 3363 Iranian adults were examined using a validated dish-based 106-item Semi-quantitative Food Frequency Questionnaire (DS-FFQ). Coffee and caffeine intake was assessed using the DS-FFQ. IBS was assessed using a modified Persian version of Rome III questionnaire. Binary logistic regression, in which the effect of several potential confounders were controlled for, was used to examine the association between coffee and caffeine intake and prevalence of IBS and its subtypes. To identify the association with severity of IBS symptoms, we applied ordinal logistic regression.

Results: After adjustment for potential confounders, we found that individuals who were taking coffee weekly or more had greater odds of IBS (OR:1.50; 95\% Cl: 1.07-2.11) than those who never drinking coffee. In addition, participants in the top tertile of caffeine intake had $49 \%$ greater odds of IBS compared to those in the bottom tertile (OR: 1.49; 95\% Cl: 1.16-1.90). By gender, this association was observed among women, but not in men (for coffee: OR: 1.50; 95\% Cl: 1.00-2.57 and for caffeine: OR: 1.50; 95\% Cl: 1.12-2.02). In addition, a significant positive association was seen between caffeine intake and odds of IBS among subjects with BMI $\geq 25$ $\mathrm{kg} / \mathrm{m}^{2}$ (OR: 1.76; $95 \% \mathrm{Cl}: 1.22-2.53$ ). There was no significant association between coffee and caffeine intake and IBS severity.

Conclusion: Coffee and caffeine consumption was associated with increased odds of IBS, in particular among women and those with $\mathrm{BMI} \geq 25 \mathrm{~kg} / \mathrm{m}^{2}$.

\section{Introduction}

Irritable Bowel Syndrome (IBS) is a common disorder of the gastrointestinal (GI) tract. In USA, $10 \%$ to $20 \%$ of the adult population suffer from IBS [1, 2]. It is not directly associated with increased mortality rates, but it is associated with reduced health-related quality of life $[3,4]$. In addition, reduced productivity and high medical costs imposes a significant burden to both patients and the society [5]. Therefore, identification and modification of its contributing factors is of high priority.

Although, the interaction between brain and the gut, disturbance in the gut neuroendocrine, aberrant central nervous system, gut dysmotility and intestinal microbiota are involved in IBS development [6, 7], it is well-documented that diet along with other lifestylerelated variables are among the main risk factors. Almost $50 \%$ of patients with IBS have experienced exacerbation of symptoms after eating $[8,9]$. In addition, consumption of low fat diet, poorly absorbed carbohydrates and spicy foods has been associated with reduced IBS symptoms $[10,11]$.

Coffee is a popular beverage with well-known effects on central nervous system [12], gut microbiome [13], gastrointestinal function and gut motility [14], however, few studies have examined the association between coffee and caffeine intake and odds of IBS. Bohn et.al. [15] investigated the effect of coffee intake on severity of IBS symptoms in a cross-sectional study on 197 IBS patients. They introduced coffee as one of top ten foods causing dyspepsia, pain, and loose stools in IBS patients. It must be kept in mind that the results of their study cannot be generalized to other societies with different lifestyle habits. In addition, they have examined such an association in patients with IBS, not the whole general population to find the association between coffee intake with IBS per se. To our knowledge, there is no study examining the association between coffee and caffeine intake and odds of IBS and its severity in a general population. Given the nutrition transition in developing countries and changing habits in these countries from tea consumption to coffee consumption, assessing the association between coffee and caffeine intake and odds of IBS is particularly relevant in these populations. Therefore, the aim of this study was to investigate the association between coffee and caffeine intake and odds of IBS and its severity in Iranian adult population.

\section{Methods And Materials}

Participants: The present cross-sectional study was conducted within the framework of the SEPAHAN (Study on the Epidemiology of Psychological, Alimentary Health and Nutrition) project, a cross-sectional study that investigated the prevalence of functional gastrointestinal disorders (FGIDs) and their relationship to lifestyle factors. Detailed information about data collection methods in SEPAHAN project has been published previously [16]. In brief, this study was performed among Iranian general adults working in 50 
different healthcare centers affiliated to Isfahan University of Medical Sciences (IUMS) across Isfahan province. In this project, data were collected in two main phases between April 2010 and May 2010. To collect information about anthropometric indices, demographic and lifestyle factors, including dietary intakes and physical activity, self-administered questionnaires distributed among 10,087 subjects in the first phase, and 8,691 participants returned the completed questionnaires (response rate: $86.16 \%$ ). In the second phase, data regarding gastrointestinal health were collected (response rate: 64.6\%). Finally, we were able to match 4,763 questionnaires in the second phase with their corresponding questionnaires in the first phase. In the current study, we excluded subjects who had total daily energy intakes outside the range of $800-4200 \mathrm{kcal} / \mathrm{d}$ as well as those that had missing data on any relevant variable. Therefore, data from 3,363 subjects, for whom complete information about both dietary intakes and IBS were available, were included in the current analysis. All participants provided written informed consent forms. The study protocol was ethically approved by the Regional Bioethics Committee of Isfahan University of Medical Sciences.

Dietary intakes assessment: Dietary data were collected using a Willett-format Dish-based 106-item Semi-quantitative Food Frequency Questionnaire (DS-FFQ), which was designed and validated specifically for Iranian adults. Detailed information about the design, foods included as well as the face validity of this questionnaire has been reported elsewhere [17]. To develop the questionnaire, a comprehensive list of foods and dishes commonly consumed by Iranian adults was constructed. Then, we chose those foods that were nutrient-rich, consumed reasonably often, or contributed to between-persons variations. This process led to the selection of the remaining 106 food items in the questionnaire. Briefly, the questionnaire contained five categories of foods and dishes: (1) mixed dishes (cooked or canned, 29 items); (2) carbohydrate-based foods (different types of bread, cakes, biscuits and potato, 10 items); (3) dairy products (dairies, butter and cream, 9 items); (4) fruits and vegetables (22 items); and (5) miscellaneous food items and beverages (including sweets, fast foods, nuts, desserts and beverages, 36 items). For each food item, a commonly consumed portion size was defined. Participants were asked to report their dietary intakes of foods and mixed dishes based on nine multiplechoice frequency response categories varying from "never or less than once a month" to "12 or more times per day." The frequency response categories for the food list varied from 6 to 9 choices. For foods consumed infrequently, we omitted the highfrequency categories, while for common foods with a high consumption, the number of multiplechoice categories increased. For instance, the frequency response for tea consumption included 9 categories, as follows: never or less than $1 \mathrm{cup} / \mathrm{month}, 1-3$ cups/month, 1-3 cups/week, 4-6 cups/week, 1 cup/day, 2-4 cups/day, 5-7 cups/day, 8-11 cups/day and $\geq 12$ cups/day. Finally, to convert the food items into grams, we computed the amount of each portion size based on the booklet of "household measures" [18] and then computed the amount of intake by considering the frequency of consumption of each food item.

The validity of DS-FFQ was examined in a subgroup of 200 randomly selected participants of the SEPAHAN project. All participants in the validation study completed the DS-FFQ at study baseline and 6 mo later. During this validation study, participants provided three detailed dietary records that were used as the gold standard. As shown in earlier studies, it seems that this questionnaire provides reasonably valid measures of long-term dietary intakes.

Calculation of coffee and caffeine intake: To assess coffee intake, participants were requested to report the average number of glasses of coffee they usually consume in the preceding year. They were able to choose one of these frequency response categories: "never or < 1 glass/month", "1-3 glasses/month", "1 glass/week", "2-4 glasses/week", "5-6 glasses/week", "1 glass/day", "2-3 glasses/day", "4-5 glasses/day" and " $\geq 6$ glasses of coffee in a day". Total caffeine intake was estimated by summing of the caffeine participants took from all caffeine-containing foods and beverages.

Assessment of IBS: A modified Persian version of the Rome III questionnaire [19], as part of the main comprehensive questionnaire, was used for assessment of IBS. During the face validation of the questionnaire, we found that most participants were unable to distinguish between the descriptors used in the original Rome III questionnaire (never, less than $1 \mathrm{~d}$ a month, $1 \mathrm{~d}$ a month, 2-3 $\mathrm{d}$ a month, $1 \mathrm{~d}$ a week, more than $1 \mathrm{~d}$ a week, every day). Therefore, we modified the rating scales to consist of only four descriptors (i.e., never or rarely, sometimes, often, and always). We also decided to ask about the presence of each symptom in the previous 3 mo instead of questioning patients about the beginning of each symptom $>6$ mo before the evaluation, which already exists in original Rome III questionnaire. IBS was defined according to Rome III criteria as having recurrent abdominal pain or discomfort, at least sometimes, in the previous 3 mo associated with two or more of these criteria: improvement with defecation, at least sometimes, and onset associated with change in frequency or form (appearance) of stool, at least sometimes. IBS with constipation (IBS-C) was defined as having IBS and both of the following criteria: hard or lumpy stools at least sometimes and lack of loose, mushy, or watery stools. IBS with diarrhea (IBS-D) was defined as having IBS and both of the following criteria: lack of hard or lumpy stools and 
loose, mushy, or watery stools at least sometimes. Mixed IBS (IBS-M) was defined as having IBS and both of the following criteria: hard or lumpy stools at least sometimes and loose, mushy, or watery stools at least sometimes. The severity of IBS was examined by asking participants about the severity of their abdominal pain in the previous 3 months. They were able to choose one of these responses: mild, moderate, severe, or very severe.

Assessment of other variables: Required information on other variables including age, sex, marital status, smoking status, medication use, and disease history (diabetes and colitis) was obtained from demographic and medical history questionnaires. Data on height, weight and waist circumference (WC) were collected using a self-reported questionnaire. Physical activity was assessed using the General Practice Physical Activity Questionnaire [20], and participants were classified into two categories: physically active $(\geq 1 \mathrm{~h} / \mathrm{wk})$ and physically inactive $(<1 \mathrm{~h} / \mathrm{wk})$. Data on diet-related practices including meal regularity (often or always/never or occasionally), chewing efficiency (a lot/not a lot), breakfast skipping (skipper/non-skipper) and intra-meal fluid intake ( $<3$ glasses $/ \geq 3$ glasses) were also assessed through the use of pretested questionnaire. Dental status was also examined and subjects were categorized as "having all teeth", "lost 1-5 teeth" and "lost > 5 teeth". Anthropometric measures including weight, height, and waist circumference were assessed using a self-administered questionnaire. The validity of self-reported values of weight, height, and waist circumferences (WC) was examined in a pilot study on 200 participants from the same population. In the validation study, self-reported values of anthropometric indices were compared with actually measured values. The correlation coefficients for self-reported weight, height, and WC versus corresponding measured values were $0.95(P<0.001), 0.83(P<0.001)$, and $0.60(P<0.001)$, respectively. Body Mass Index (BMI) was calculated by dividing weight $(\mathrm{kg})$ to height $\left(\mathrm{m}^{2}\right)$. The correlation coefficient for computed BMI from self-reported values, and the one from measured values was $0.70(P<0.001)$.

Statistical analysis: General characteristics of study participants across categories of coffee and caffeine intake were presented as means \pm SD s for continuous variables and percentages for categorical variables. To examine the differences across categories, we used ANOVA for continuous variables and chi-square test for categorical variables. We used binary logistic regression to estimate ORs and $95 \% \mathrm{Cls}$ for the presence of IBS and its subtypes across categories of coffee and caffeine intake in crude and multivariable-adjusted model. The trend of ORs across categories of coffee and caffeine intake was determined by considering categories of coffee and caffeine intake as ordinal variables in the logistic regression analysis. We also used multivariable ordinal logistic regression to estimate ORs and $95 \%$ Cls for assessing IBS severity (mild/moderate/severe/very severe) across categories of coffee and caffeine intake in crude and multivariable-adjusted model. In these analyses, age, sex (male/female), energy intake (continuous), BMI (continuous), physical activity ( $<1 \mathrm{~h} /$ week/ $\geq 1 \mathrm{~h} /$ week), smoking status (non-smoker/former smokers and current smokers), medication use (yes/no), self-reported diabetes (yes/no) and colitis (yes/no), psychological distress (yes/no), meal regularity (often or always/never or occasionally), chewing sufficiency (a lot/not a lot), intra-meal fluid consumption ( $<3$ glasses/ $\geq 3$ glasses), breakfast skipping (skipper/non-skipper), and dental status (have all teeth/lost 1-5 teeth/lost $>5$ teeth) were adjusted for in the multivariable model. All statistical analyses were done using the Statistical Package for Social Sciences (version 20; SPSS Inc.). $\mathrm{P}<0.05$ was considered as statistically significant.

\section{Results}

General characteristics of study participants across categories of coffee and caffeine intake are shown in Table 1. Participants who consumed coffee weekly or more were more likely to be physically active, current smoker, and had higher energy intakes and less likely to lose their teeth compared with those who did not consume coffee. In terms of caffeine intake, those in the top tertile of caffeine intake were more likely to be older, current smoker, had regular meal pattern, and had higher energy intakes and less likely to be female and lose their teeth compared with those in the bottom tertile. No other significant differences were found in terms of other variables.

Crude and multivariable-adjusted odds ratios and $95 \%$ confidence intervals $(95 \% \mathrm{Cl})$ for IBS across categories of coffee and caffeine intake are presented in Table 2. In the whole study population, those who consumed coffee weekly or more had higher odds of IBS compared to those who did not take coffee (OR:1.50; 95\% Cl: 1.07-2.11). By sex, women in the top category of coffee consumption had $50 \%$ greater chance of IBS compared with those in the bottom category (OR: 1.50; 95\% Cl: 1.00-2.57). However, this association was not found in men. By BMl, we failed to find any significant association between coffee consumption and odds of IBS in normal weight $\left(B M l<25 \mathrm{~kg} / \mathrm{m}^{2}\right)$ and overweight or obese $\left(\mathrm{BMl} \geq 25 \mathrm{~kg} / \mathrm{m}^{2}\right)$ individuals either before or after controlling for potential confounders. 
Individuals in top tertile of caffeine intake had greater odds of IBS compared with those in the bottom tertile (OR: 1.49; $95 \%$ Cl: 1.161.90). When we did the analyses by sex, we did not observe any significant association between caffeine intake and odds of IBS among men; however, a significant positive association was seen among women (OR: 1.50; 95\% Cl: 1.12-2.02). By BMl, overweight subjects $\left(B M I \geq 25 \mathrm{~kg} / \mathrm{m}^{2}\right)$ in the highest tertile of caffeine intake were $76 \%$ more likely to have IBS compared with those in the lowest tertile (OR: 1.76; $95 \% \mathrm{Cl}$ : 1.22-2.53). However, no significant association was found among normal weight subjects (BMl<25 $\left.\mathrm{kg} / \mathrm{m}^{2}\right)$.

Crude and multivariable-adjusted ORs and $95 \%$ Cls for IBS severity across different categories of coffee and caffeine intake are presented in Table 3. No significant association was found between coffee or caffeine consumption and IBS severity. The same findings were also observed when we analyzed data stratified by gender or BMI status.

Crude and multivariable-adjusted ORs and $95 \%$ Cls for IBS subtypes across different categories of coffee and caffeine intake are presented in Table 4. After controlling for potential confounders, we found that those who were taking coffee weekly or more had $75 \%$ higher odds of IBS-C compared with those who did not consume (OR: 1.75; 95\% Cl: 1.06-2.88). In addition, participants in the highest tertile of caffeine intake had higher odds of IBS-C compared with those in the lowest tertile (OR: 1.52; 95\% Cl: 1.05-2.21). No other overall association was seen between coffee or caffeine consumption and other types of IBS.

\section{Discussion}

In this cross-sectional study, we found that high coffee and caffeine intake was associated with a greater odds of IBS in the whole study population. By gender, the association was significantly positive among women, but not in men. In addition, a significant positive association was seen between caffeine intake and odds of IBS among subjects with $B M I \geq 25 \mathrm{~kg} / \mathrm{m}^{2}$.

We found that coffee and caffeine consumption was associated with a greater odds of IBS. In line with our findings, several other studies have also indicated that coffee consumption was associated with symptoms of IBS [11,21, 22]. In a study in the Netherlands, coffee intake by IBS patients was not associated with functional bowel symptoms [23]. However, the prevalence of IBS in general Dutch adult population appears to be lower than that in other countries. Several mechanisms may explain the significant positive association between coffee and caffeine intake and odds of IBS. Impaired gastrointestinal neural control due to dysregulations in hypothalamic-anterior pituitary-adrenocortical axis (HPA) and increased secretion of stress hormones has been implicated in the pathophysiology of IBS [24]. Some studies have suggested that coffee may activate the HPA axis and elevate the stress hormones including cortisol, epinephrine and norepinephrine [25, 26]. Therefore, coffee consumption may increase the chance of IBS by altering HPA function. In addition, both coffee and caffeine stimulate gastric acid secretion and this may irritate the intestine and might lead to injury of the intestinal tissue [27, 28]. Finally, caffeine blocks binding of gamma aminobutyric acid (GABA) to GABA receptors [29] and lack of GABA's effect help increasing the irritability and hyperactivity of the intestine [30].

In our study, we found a gender difference in the association between coffee and caffeine intake and odds of IBS; such that high consumption of coffee and caffeine intake was linked to a greater chance of IBS in women, but not in men. The slower metabolism of caffeine among women than that in men might be a possible explanation for this gender discrepancy [31]. In addition, we observed a significant association between caffeine intake and odds of IBS among overweight or obese (BMI $\left.\geq 25 \mathrm{~kg} / \mathrm{m}^{2}\right)$, but not in normal weight subjects $\left(\mathrm{BMl}<25 \mathrm{~kg} / \mathrm{m}^{2}\right)$. Previous studies showed that the metabolism of caffeine is slower in overweight or obese people compared to that in normal-weight individuals [32]. This may explain, at least in part, the positive association between caffeine consumption and odds of IBS in this population.

We failed to find any significant relationship between coffee and caffeine intake and severity of IBS symptoms. It must be noted that number of people with IBS in this study was 748 subjects, most of them had mild to moderate IBS symptoms. Therefore, this might partly justify this finding. In terms of IBS subtypes, we found that coffee and caffeine intake was associated with increased chance of IBS-C. One explanation for this observation might be that the diuretic effect of caffeine can in turn lead to dehydration [33] and finally constipation. Decreased absorption of magnesium following coffee consumption may be another explanation for this finding [34]. Laxative effect of magnesium is important for maintaining bowel regularity [35].

This study has several strengths. Being the first study examining the association of coffee and caffeine intake and odds of IBS in general population, large sample size of the study and considering the wide range of potential confounders in statistical analyses

Page 5/11 
are among the strengths of the study. However, some limitations must be considered. The cross-sectional design of the study does not allow us to confer causual relationships between coffee and caffeine intake and IBS. In this study, we used self-reported questionnaires to assess the exposure and outcome. Therefore, misclassification of study participants in terms of exposure and outcome might be occured.

\section{Conclusion}

The present study showed a significant positive assosiation between coffee and caffeine intake and odds of IBS in the whole population. This association was also observed among women, but not in men. In addition, we found a significant positive association between caffeine intake and odds of IBS among subjects with $B M I \geq 25 \mathrm{~kg} / \mathrm{m}^{2}$.

\section{Abbreviations}

IBS: Irritable bowel syndrome, DS-FFQ: Dish-based Semi-quantitative Food Frequency Questionnaire, GI: Gastrointestinal tract, SEPAHAN: Study on the Epidemiology of Psychological, Alimentary Health and Nutrition project, FGIDs: Functional Gastrointestinal Disorders, IUMS: Isfahan University of Medical Sciences, IBS-C: IBS with constipation. IBS-D: IBS with diarrhea, IBS-M: Mixed IBS, WC: waist circumference, HPA: Hypothalamic-anterior pituitary-adrenocortical axis, GABA: Gamma aminobutyric acid.

\section{Declarations}

\section{ACKNOWLEDGMENTS}

The authors are thankful to participants of SEPAHAN project and authorities of Isfahan University of Medical Sciences for their excellent cooperation.

Ethical Approval and Consent to participate: The study protocol was ethically approved by the Regional Bioethics Committee of Isfahan University of Medical Sciences. All participants provided written informed consent forms.

\section{Consent for publication}

All authors of this manuscript declare their consent for publication.

\section{Availability of data and materials}

The dataset used and analyzed during the current study is available from the corresponding author on a reasonable request.

\section{Competing interests}

The authors declare no conflicts of interest.

\section{Funding}

The authors received no specific funding for this study.

\section{Authors' contributions}

GK and ASM contributed to the search, statistical analyses, data interpretation and manuscript drafting. AHK and PA contributed to the conception, design and manuscript drafting. AE contributed to the conception, design, statistical analyses, data interpretation and manuscript drafting. AE supervised the study. All authors approved the final manuscript for submission.

\section{References}

1. Lovell RM, Ford AC. Global prevalence of and risk factors for irritable bowel syndrome: a meta-analysis. Clinical gastroenterology and hepatology : the official clinical practice journal of the American Gastroenterological Association. 2012;10(7):712-21.e4. 
2. Longstreth GF, Thompson WG, Chey WD, Houghton LA, Mearin F, Spiller RC. Functional bowel disorders. Gastroenterology. 2006;130(5):1480-91.

3. Whitehead WE, Burnett CK, Cook EW, 3rd, Taub E. Impact of irritable bowel syndrome on quality of life. Digestive diseases and sciences. 1996;41(11):2248-53.

4. Gralnek IM, Hays RD, Kilbourne A, Naliboff B, Mayer EA. The impact of irritable bowel syndrome on health-related quality of life. Gastroenterology. 2000;119(3):654-60.

5. Inadomi JM, Fennerty MB, Bjorkman D. Systematic review: the economic impact of irritable bowel syndrome. Alimentary pharmacology \& therapeutics. 2003;18(7):671-82.

6. Drossman DA, Camilleri M, Mayer EA, Whitehead WE. AGA technical review on irritable bowel syndrome. Gastroenterology. 2002;123(6):2108-31.

7. Saha L. Irritable bowel syndrome: pathogenesis, diagnosis, treatment, and evidence-based medicine. World journal of gastroenterology. 2014;20(22):6759-73.

8. Cabre E. Irritable bowel syndrome: can nutrient manipulation help? Current opinion in clinical nutrition and metabolic care. 2010;13(5):581-7.

9. Ragnarsson G, Bodemar G. Pain is temporally related to eating but not to defaecation in the irritable bowel syndrome (IBS). Patients' description of diarrhea, constipation and symptom variation during a prospective 6-week study. European journal of gastroenterology \& hepatology. 1998;10(5):415-21.

10. Halmos EP, Power VA, Shepherd SJ, Gibson PR, Muir JG. A diet low in FODMAPs reduces symptoms of irritable bowel syndrome. Gastroenterology. 2014;146(1):67-75.e5.

11. Simren M, Mansson A, Langkilde AM, Svedlund J, Abrahamsson H, Bengtsson U, et al. Food-related gastrointestinal symptoms in the irritable bowel syndrome. Digestion. 2001;63(2):108-15.

12. Nehlig A, Daval JL, Debry G. Caffeine and the central nervous system: mechanisms of action, biochemical, metabolic and psychostimulant effects. Brain research Brain research reviews. 1992;17(2):139-70.

13. Nishitsuji K, Watanabe S, Xiao J, Nagatomo R, Ogawa H, Tsunematsu T, et al. Effect of coffee or coffee components on gut microbiome and short-chain fatty acids in a mouse model of metabolic syndrome. Scientific reports. 2018;8(1):16173.

14. Brown SR, Cann PA, Read NW. Effect of coffee on distal colon function. Gut. 1990;31(4):450-3.

15. Bohn L, Storsrud S, Tornblom H, Bengtsson U, Simren M. Self-reported food-related gastrointestinal symptoms in IBS are common and associated with more severe symptoms and reduced quality of life. The American journal of gastroenterology. 2013;108(5):634-41.

16. Adibi P, Keshteli AH, Esmaillzadeh A, Afshar H, Roohafza H, Bagherian-Sararoudi R, et al. The study on the epidemiology of psychological, alimentary health and nutrition (SEPAHAN): overview of methodology. J Res Med Sci. 2012;17(5):S292-S8.

17. Keshteli A, Esmaillzadeh A, Rajaie S, Askari G, Feinle-Bisset C, Adibi P. A Dish-based Semi-quantitative Food Frequency Questionnaire for Assessment of Dietary Intakes in Epidemiologic Studies in Iran: Design and Development. International journal of preventive medicine. 2014;5(1):29-36.

18. Ghaffarpour M H-RA, Kianfar H (1999) The manual, for household measures cyfaep, 1-40 ofTNOK.

19. Lacy BE, Patel NK. Rome Criteria and a Diagnostic Approach to Irritable Bowel Syndrome. Journal of clinical medicine. 2017;6(11).

20. Department of Health (2006) The general practice physical activity questionnaire. Department of Health L.

21. Monsbakken KW, Vandvik PO, Farup PG. Perceived food intolerance in subjects with irritable bowel syndrome-- etiology, prevalence and consequences. European journal of clinical nutrition. 2006;60(5):667-72.

22. Faresjo A, Johansson S, Faresjo T, Roos S, Hallert C. Sex differences in dietary coping with gastrointestinal symptoms. European journal of gastroenterology \& hepatology. 2010;22(3):327-33.

23. Boekema PJ, van Dam van Isselt EF, Bots ML, Smout AJ. Functional bowel symptoms in a general Dutch population and associations with common stimulants. The Netherlands journal of medicine. 2001;59(1):23-30.

24. Chang L, Sundaresh S, Elliott J, Anton PA, Baldi P, Licudine A, et al. Dysregulation of the hypothalamic-pituitary-adrenal (HPA) axis in irritable bowel syndrome. Neurogastroenterology and motility : the official journal of the European Gastrointestinal

Page 7/11 
Motility Society. 2009;21(2):149-59.

25. Lane JD. Neuroendocrine responses to caffeine in the work environment. Psychosomatic medicine. 1994;56(3):267-70.

26. Patz MD, Day HE, Burow A, Campeau S. Modulation of the hypothalamo-pituitary-adrenocortical axis by caffeine. Psychoneuroendocrinology. 2006;31(4):493-500.

27. Borger HW, Schafmayer A, Arnold R, Becker HD, Creutzfeldt W. [The influence of coffee and caffeine on gastrin and acid secretion in man (author's transl)]. Deutsche medizinische Wochenschrift (1946). 1976;101(12):455-7.

28. Glatzel H, Hackenberg K. [Effects of caffeine containing and decaffeinated coffee on the digestive functions. X-ray studies of the secretion and peristalsis of stomach, intestines and gallbladder]. Medizinische Klinik. 1967;62(16):625-8.

29. Roca DJ, Schiller GD, Farb DH. Chronic caffeine or theophylline exposure reduces gamma-aminobutyric acid/benzodiazepine receptor site interactions. Molecular pharmacology. 1988;33(5):481-5.

30. Lea R, Whorwell PJ. New insights into the psychosocial aspects of irritable bowel syndrome. Current gastroenterology reports. 2003;5(4):343-50.

31. Rasmussen BB, Brix TH, Kyvik KO, Brosen K. The interindividual differences in the 3-demthylation of caffeine alias CYP1A2 is determined by both genetic and environmental factors. Pharmacogenetics. 2002;12(6):473-8.

32. Kamimori GH, Somani SM, Knowlton RG, Perkins RM. The effects of obesity and exercise on the pharmacokinetics of caffeine in lean and obese volunteers. European journal of clinical pharmacology. 1987;31(5):595-600.

33. Babb RR. Coffee, sugars, and chronic diarrhea. Why a dietary history is important. Postgraduate medicine. 1984;75(8):82, 6-7.

34. Bergman EA, Massey LK, Wise KJ, Sherrard DJ. Effects of dietary caffeine on renal handling of minerals in adult women. Life sciences. 1990;47(6):557-64.

35. Donowitz M, Rood RP. Magnesium hydroxide: new insights into the mechanism of its laxative effect and the potential involvement of prostaglandin E2. Journal of clinical gastroenterology. 1992;14(1):20-6.

\section{Tables}

ues are mean $\pm \mathrm{SD}$, unless indicated; ${ }^{\mathrm{b}} \mathrm{ANOVA}$ for continuous variables and chi-squared test for categorical variables

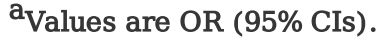

${ }^{\mathrm{b}}$ Adjusted for age, sex, energy, BMI, physical activity, smoking status, medication use, disease history (diabetes, colitis), psychological distress, regular meal pattern, chewing sufficiency, fluid consumption, breakfast skipping and dental status.

CAdjusted for age, energy, BMI, physical activity, smoking status, medication use, disease history (diabetes, colitis), psychological distress, regular meal pattern, chewing sufficiency, fluid consumption, breakfast skipping and dental status.

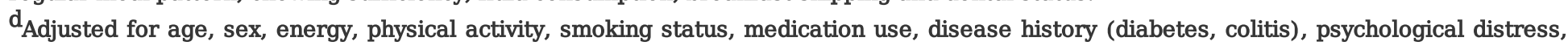
regular meal pattern, chewing sufficiency, fluid consumption, breakfast skipping and dental status.
}

\footnotetext{
${ }^{\mathrm{a}}$ Values are OR (95\% CIs).

${ }^{\mathrm{b}}$ Adjusted for age, sex, energy, BMI, physical activity, smoking status, medication use, disease history (diabetes, colitis), psychological distress, regular meal pattern, chewing sufficiency, fluid consumption, breakfast skipping and dental status.

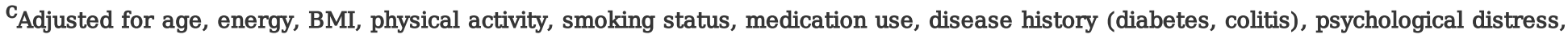
regular meal pattern, chewing sufficiency, fluid consumption, breakfast skipping and dental status.
}

\footnotetext{
${ }^{\mathrm{a}}$ Values are OR (95\% CIs).

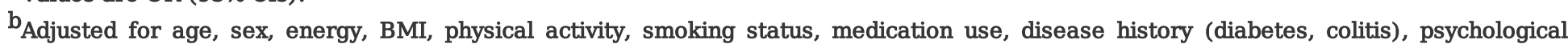
distress, regular meal pattern, chewing sufficiency, fluid consumption, breakfast skipping and dental status.
} 
Table 1: General characteristics of study participants across categories of coffee and caffeine intake ${ }^{\mathrm{a}}$

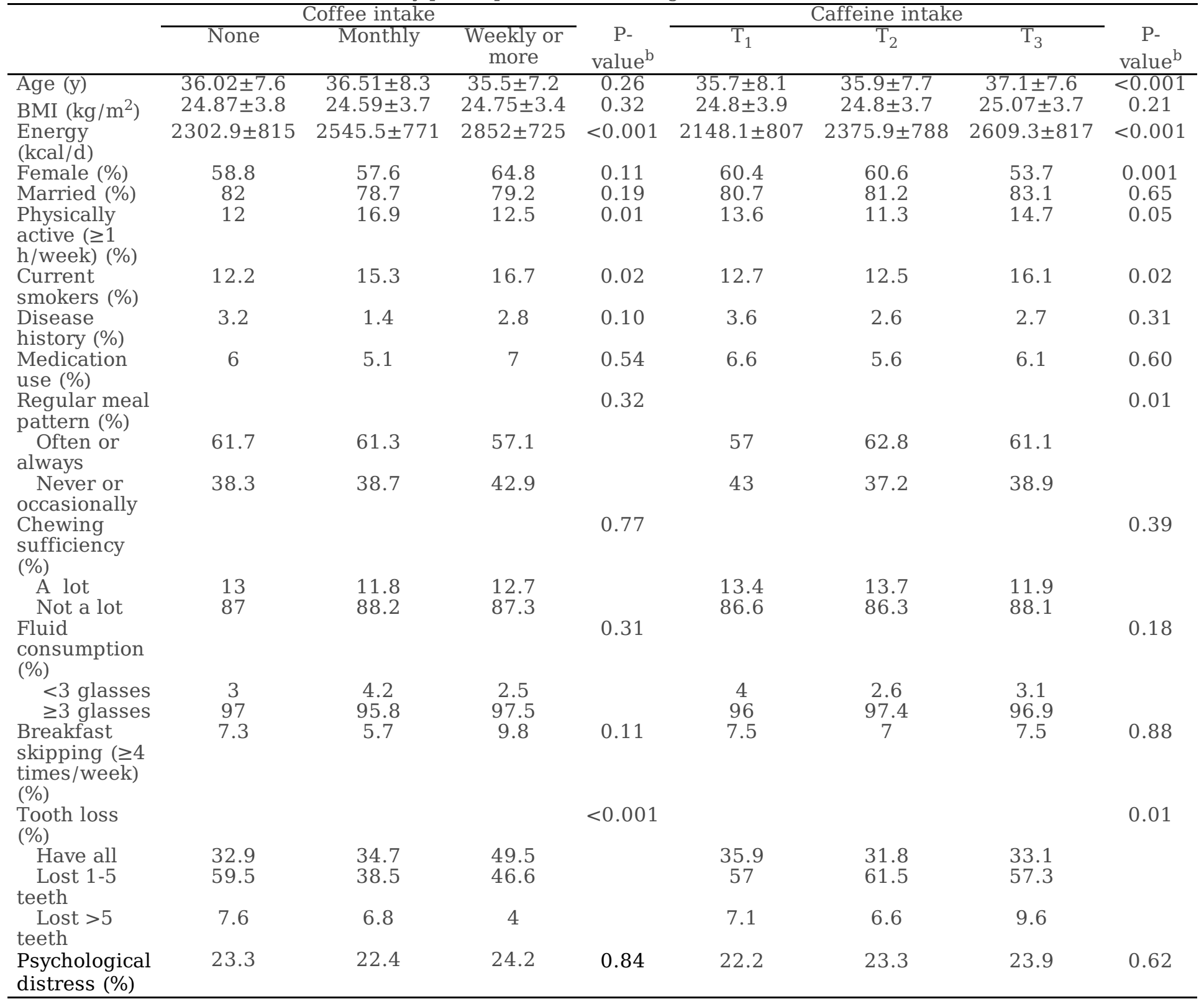


Table 2: Crude and multivariable-adjusted ORs and 95\% CIs for IBS across categories of coffee and caffeine intake $^{\mathrm{a}}$

\begin{tabular}{|c|c|c|c|c|c|c|c|c|}
\hline & \multicolumn{3}{|c|}{ Coffee intake } & \multirow[b]{2}{*}{$\begin{array}{l}\mathrm{P}- \\
\text { trend }\end{array}$} & \multicolumn{3}{|c|}{ Caffeine intake } & \multirow[b]{2}{*}{$\begin{array}{l}\mathrm{P}- \\
\text { trend }\end{array}$} \\
\hline & $\begin{array}{c}\text { None } \\
(\mathrm{n}=2072)\end{array}$ & $\begin{array}{l}\text { Monthly } \\
(\mathrm{n}=432)\end{array}$ & $\begin{array}{c}\text { Weekly or } \\
\text { more } \\
(\mathrm{n}=247)\end{array}$ & & $\begin{array}{c}\mathrm{T}_{1} \\
(\mathrm{n}=966)\end{array}$ & $\begin{array}{c}\mathrm{T}_{2} \\
(\mathrm{n}=1020)\end{array}$ & $\begin{array}{c}\mathrm{T}_{3} \\
(\mathrm{n}=1001)\end{array}$ & \\
\hline Whole population & & & & & & & & \\
\hline Crude & 1.00 & $\begin{array}{l}1.14(0.90- \\
1.43)\end{array}$ & $\begin{array}{l}1.21(0.91- \\
1.61)\end{array}$ & 0.10 & 1.00 & $\begin{array}{c}1.18(0.96- \\
1.45)\end{array}$ & $\begin{array}{c}1.32(1.08- \\
1.61)\end{array}$ & 0.006 \\
\hline $\begin{array}{l}\text { Multivariable- } \\
\text { adjusted }^{\mathrm{b}}\end{array}$ & 1.00 & $\begin{array}{c}1.35(1.03- \\
1.77)\end{array}$ & $\begin{array}{l}1.50(1.07- \\
2.11)\end{array}$ & 0.003 & 1.00 & $\begin{array}{c}1.28(1.01- \\
1.63)\end{array}$ & $\begin{array}{l}1.49(1.16- \\
1.90)\end{array}$ & 0.001 \\
\hline \multirow{2}{*}{ Crude } & & & & & & & & \\
\hline & 1.00 & $\begin{array}{c}0.88(0.59- \\
1.31)\end{array}$ & $\begin{array}{c}1.17(0.71- \\
1.94)\end{array}$ & 0.81 & 1.00 & $\begin{array}{c}1.17(0.83- \\
1.66)\end{array}$ & $\begin{array}{c}1.23(0.88- \\
1.72)\end{array}$ & 0.21 \\
\hline $\begin{array}{l}\text { Multivariable- } \\
\text { adjusted }^{\mathrm{C}}\end{array}$ & 1.00 & $\begin{array}{c}1.05(0.65- \\
1.70)\end{array}$ & $\begin{array}{c}1.48(0.77- \\
2.83)\end{array}$ & 0.28 & 1.00 & $\begin{array}{l}1.45(0.93- \\
2.27)\end{array}$ & $\begin{array}{l}1.50(0.96- \\
2.34)\end{array}$ & 0.08 \\
\hline \multicolumn{9}{|l|}{ Female } \\
\hline Crude & 1.00 & $\begin{array}{c}1.32(0.99- \\
1.76)\end{array}$ & $\begin{array}{c}1.20(0.85- \\
1.70)\end{array}$ & 0.08 & 1.00 & $\begin{array}{c}1.18(0.92- \\
1.53)\end{array}$ & $\begin{array}{c}1.44(1.11- \\
1.86)\end{array}$ & 0.005 \\
\hline $\begin{array}{l}\text { Multivariable- } \\
\text { adjusted }^{\mathrm{C}}\end{array}$ & 1.00 & $\begin{array}{l}1.54(1.10- \\
2.15)\end{array}$ & $\begin{array}{l}1.50(1.00- \\
2.57)\end{array}$ & 0.006 & 1.00 & $\begin{array}{c}1.22(0.92- \\
1.63)\end{array}$ & $\begin{array}{l}1.50(1.12- \\
2.02)\end{array}$ & 0.007 \\
\hline \multicolumn{9}{|l|}{$\mathrm{BMI}<25\left(\mathrm{~kg} / \mathrm{m}^{2}\right)$} \\
\hline Crude & 1.00 & $\begin{array}{c}0.99(0.72- \\
1.37)\end{array}$ & $\begin{array}{c}1.12(0.76- \\
1.64)\end{array}$ & 0.61 & 1.00 & $\begin{array}{c}1.08(0.81- \\
1.42)\end{array}$ & $\begin{array}{c}1.10(0.83- \\
1.46)\end{array}$ & 0.47 \\
\hline $\begin{array}{l}\text { Multivariable- } \\
\text { adjusted }^{\mathrm{d}}\end{array}$ & 1.00 & $\begin{array}{c}1.29(0.90- \\
1.86)\end{array}$ & $\begin{array}{l}1.47(0.95- \\
2.29)\end{array}$ & 0.04 & 1.00 & $\begin{array}{l}1.19(0.86- \\
1.63)\end{array}$ & $\begin{array}{l}1.28(0.91- \\
1.79)\end{array}$ & 0.14 \\
\hline \multicolumn{9}{|l|}{$\mathrm{BMI} \geq 25\left(\mathrm{~kg} / \mathrm{m}^{2}\right)$} \\
\hline Crude & 1.00 & $\begin{array}{c}1.33(0.94- \\
1.87)\end{array}$ & $\begin{array}{c}1.23(0.79- \\
1.93)\end{array}$ & 0.12 & 1.00 & $\begin{array}{c}1.39(1.02- \\
1.90)\end{array}$ & $\begin{array}{c}1.57(1.16- \\
2.13)\end{array}$ & 0.003 \\
\hline $\begin{array}{l}\text { Multivariable- } \\
\text { adjusted }^{\mathrm{d}}\end{array}$ & 1.00 & $\begin{array}{l}1.53(1.02- \\
2.28)\end{array}$ & $\begin{array}{l}1.59(0.92- \\
2.74)\end{array}$ & 0.02 & 1.00 & $\begin{array}{l}1.40(0.97- \\
2.03)\end{array}$ & $\begin{array}{l}1.76(1.22- \\
2.53)\end{array}$ & 0.002 \\
\hline
\end{tabular}

Table 3: Crude and multivariable-adjusted ORs and 95\% CIs for IBS severity across categories of coffee and caffeine intake ${ }^{\mathrm{a}}$

\begin{tabular}{|c|c|c|c|c|c|c|}
\hline & \multicolumn{3}{|c|}{ Coffee intake } & \multicolumn{3}{|c|}{ Caffeine intake } \\
\hline & $\begin{array}{c}\text { None } \\
(\mathrm{n}=2072)\end{array}$ & $\begin{array}{l}\text { Monthly } \\
(\mathrm{n}=432)\end{array}$ & $\begin{array}{c}\text { Weekly or more } \\
(\mathrm{n}=247)\end{array}$ & $\begin{array}{c}\mathrm{T}_{1} \\
(\mathrm{n}=966)\end{array}$ & $\begin{array}{c}\mathrm{T}_{2} \\
(\mathrm{n}=1020)\end{array}$ & $\begin{array}{c}\mathrm{T}_{3} \\
(\mathrm{n}=1001)\end{array}$ \\
\hline \multicolumn{7}{|l|}{ Whole population } \\
\hline Crude & 1.00 & $\begin{array}{c}0.78(0.50- \\
1.22)\end{array}$ & $\begin{array}{c}1.02(0.61- \\
1.72)\end{array}$ & 1.00 & $\begin{array}{c}1.24(0.85- \\
1.82)\end{array}$ & $\begin{array}{c}1.00(0.68- \\
1.48)\end{array}$ \\
\hline $\begin{array}{l}\text { Multivariable- } \\
\text { adjusted }^{\text {b }}\end{array}$ & 1.00 & $\begin{array}{l}0.97(0.59- \\
1.61)\end{array}$ & $\begin{array}{l}0.99(0.53- \\
1.85)\end{array}$ & 1.00 & $\begin{array}{c}1.26(0.81- \\
1.96)\end{array}$ & $\begin{array}{l}1.03(0.65- \\
1.65)\end{array}$ \\
\hline \multicolumn{7}{|l|}{ Male } \\
\hline Crude & 1.00 & $\begin{array}{c}0.45(0.19- \\
1.06)\end{array}$ & $\begin{array}{c}1.11(0.45- \\
2.73)\end{array}$ & 1.00 & $\begin{array}{c}1.20(0.62- \\
2.33)\end{array}$ & $\begin{array}{c}1.16(0.61- \\
2.19)\end{array}$ \\
\hline $\begin{array}{l}\text { Multivariable- } \\
\text { adjusted }^{\mathrm{C}}\end{array}$ & 1.00 & $\begin{array}{l}0.40(0.13- \\
1.20)\end{array}$ & $\begin{array}{l}0.88(0.27- \\
2.85)\end{array}$ & 1.00 & $\begin{array}{l}0.95(0.38- \\
2.35)\end{array}$ & $\begin{array}{l}0.75(0.29- \\
1.88)\end{array}$ \\
\hline \multicolumn{7}{|l|}{ Female } \\
\hline Crude & 1.00 & $\begin{array}{l}0.99(0.58- \\
1.67)\end{array}$ & $\begin{array}{l}0.98(0.51- \\
1.86)\end{array}$ & 1.00 & $\begin{array}{l}1.26(0.80- \\
2.01)\end{array}$ & $\begin{array}{l}0.92(0.58- \\
1.48)\end{array}$ \\
\hline $\begin{array}{l}\text { Multivariable- } \\
\text { adjusted }^{c}\end{array}$ & 1.00 & $\begin{array}{l}1.27(0.70- \\
2.31)\end{array}$ & $\begin{array}{l}1.06(0.50- \\
2.25)\end{array}$ & 1.00 & $\begin{array}{l}1.39(0.82- \\
2.34)\end{array}$ & $\begin{array}{c}1.12(0.64- \\
1.98)\end{array}$ \\
\hline \multicolumn{7}{|l|}{$\mathrm{BMI}<25\left(\mathrm{~kg} / \mathrm{m}^{2}\right)$} \\
\hline Crude & 1.00 & $\begin{array}{c}0.86(0.47- \\
1.58)\end{array}$ & $\begin{array}{l}0.94(0.45- \\
1.94)\end{array}$ & 1.00 & $\begin{array}{c}1.00(0.60- \\
1.67)\end{array}$ & $\begin{array}{c}0.88(0.51- \\
1.49)\end{array}$ \\
\hline $\begin{array}{l}\text { Multivariable- } \\
\text { adjusted }^{b}\end{array}$ & 1.00 & $\begin{array}{c}0.88(0.44- \\
1.74)\end{array}$ & $\begin{array}{c}0.73(0.30- \\
1.76)\end{array}$ & 1.00 & $\begin{array}{c}1.00(0.55- \\
1.83)\end{array}$ & $\begin{array}{l}0.62(0.32- \\
1.20)\end{array}$ \\
\hline \multicolumn{7}{|l|}{$\mathrm{BMI} \geq 25\left(\mathrm{~kg} / \mathrm{m}^{2}\right)$} \\
\hline Crude & 1.00 & $\begin{array}{c}0.69(0.35- \\
1.35)\end{array}$ & $\begin{array}{c}0.94(0.42- \\
2.11)\end{array}$ & 1.00 & $\begin{array}{c}1.64(0.91- \\
2.93)\end{array}$ & $\begin{array}{c}1.15(0.65- \\
2.05)\end{array}$ \\
\hline $\begin{array}{l}\text { Multivariable- } \\
\text { adjusted }^{\mathrm{b}}\end{array}$ & 1.00 & $\begin{array}{c}1.15(0.53- \\
2.50)\end{array}$ & $\begin{array}{l}1.26(0.48- \\
3.28)\end{array}$ & 1.00 & $\begin{array}{l}1.77(0.88- \\
3.55)\end{array}$ & $\begin{array}{c}1.73(0.86- \\
3.46)\end{array}$ \\
\hline
\end{tabular}


Table 4: Crude and multivariable-adjusted ORs and 95\% CIs for IBS subtypes across categories of coffee and caffeine intake $^{\mathrm{a}}$

\begin{tabular}{cclllll}
\multicolumn{3}{c}{ Coffee intake } & & \multicolumn{3}{c}{ Caffeine intake } \\
\cline { 1 - 2 } None & Monthly & Weekly or & $\mathrm{T}_{1}$ & $\mathrm{~T}_{2}$ & $\mathrm{~T}_{3}$
\end{tabular}

$(\mathrm{n}=2072) \quad(\mathrm{n}=432) \quad$ more trend $(\mathrm{n}=966) \quad(\mathrm{n}=1020) \quad(\mathrm{n}=1001) \quad$ trend
$(\mathrm{n}=247)$

\begin{tabular}{|c|c|c|c|c|c|c|c|c|}
\hline & & & & & & & & \\
\hline $\begin{array}{l}\text { IBS-C } \\
\text { Crude }\end{array}$ & 1.00 & $\begin{array}{c}1.54(1.09- \\
2.15)\end{array}$ & $\begin{array}{l}1.80(1.21- \\
2.68)\end{array}$ & 0.001 & 1.00 & $\begin{array}{c}1.11(0.79- \\
1.55)\end{array}$ & $\begin{array}{c}1.56(1.14- \\
2.15)\end{array}$ & 0.004 \\
\hline $\begin{array}{l}\text { Multivariable- } \\
\text { adjusted }^{b} \\
\text { IBS-D }\end{array}$ & 1.00 & $\begin{array}{l}1.70(1.15- \\
2.53)\end{array}$ & $\begin{array}{c}1.75(1.06- \\
2.88)\end{array}$ & 0.003 & 1.00 & $\begin{array}{c}1.03(0.70- \\
1.50)\end{array}$ & $\begin{array}{c}1.52(1.05- \\
2.21)\end{array}$ & 0.02 \\
\hline Crude & 1.00 & $\begin{array}{c}1.11(0.71- \\
1.74)\end{array}$ & $\begin{array}{c}0.98(0.54- \\
1.77)\end{array}$ & 0.86 & 1.00 & $\begin{array}{c}1.27(0.85- \\
1.89)\end{array}$ & $\begin{array}{c}1.17(0.77- \\
1.75)\end{array}$ & 0.46 \\
\hline $\begin{array}{l}\text { Multivariable- } \\
\text { adjusted }^{\mathrm{C}} \\
\text { IBS-M }\end{array}$ & 1.00 & $\begin{array}{c}1.34(0.81- \\
2.21)\end{array}$ & $\begin{array}{c}1.15(0.59- \\
2.25)\end{array}$ & 0.39 & 1.00 & $\begin{array}{c}1.43(0.90- \\
2.27)\end{array}$ & $\begin{array}{c}1.20(0.73- \\
1.97)\end{array}$ & 0.47 \\
\hline Crude & 1.00 & $\begin{array}{c}1.05(0.64- \\
1.73)\end{array}$ & $\begin{array}{c}0.80(0.40- \\
1.62)\end{array}$ & 0.69 & 1.00 & $\begin{array}{c}1.05(0.68- \\
1.62)\end{array}$ & $\begin{array}{c}1.06(0.68- \\
1.63)\end{array}$ & 0.78 \\
\hline $\begin{array}{l}\text { Multivariable- } \\
\text { adjusted } \\
\text { IBS-U }\end{array}$ & 1.00 & $\begin{array}{l}1.27(0.73- \\
2.21)\end{array}$ & $\begin{array}{l}1.21(0.58- \\
2.53)\end{array}$ & 0.41 & 1.00 & $\begin{array}{c}1.17(0.70- \\
1.95)\end{array}$ & $\begin{array}{c}1.40(0.85- \\
2.33)\end{array}$ & 0.18 \\
\hline Crude & 1.00 & $\begin{array}{c}0.74(0.48- \\
1.15)\end{array}$ & $\begin{array}{c}0.92(0.56- \\
1.53)\end{array}$ & 0.40 & 1.00 & $\begin{array}{c}1.17(0.83- \\
1.66)\end{array}$ & $\begin{array}{c}1.13(0.80- \\
1.61)\end{array}$ & 0.48 \\
\hline $\begin{array}{l}\text { Multivariable- } \\
\text { adjusted }^{b}\end{array}$ & 1.00 & $\begin{array}{c}0.79(0.47- \\
1.32)\end{array}$ & $\begin{array}{c}1.29(0.73- \\
2.28)\end{array}$ & 0.51 & 1.00 & $\begin{array}{l}1.36(0.91- \\
2.05)\end{array}$ & $\begin{array}{l}1.33(0.87- \\
2.04)\end{array}$ & 0.18 \\
\hline
\end{tabular}

